\title{
Teaching Business Statistics: Some Useful Relationships
}

\author{
Philip F. Rice ${ }^{1} \&$ Chris Brune ${ }^{1}$ \\ ${ }^{1}$ Hickingbotham School of Business, Ouachita Baptist University, Arkadelphia, Arkansas, USA \\ Correspondence: Chris Brune, Hickingbotham School of Business, Ouachita Baptist University, Arkadelphia, AR, \\ USA. E-mail: brunec@obu.edu
}

Received: January 24, 2020

Accepted: March 20, 2020

Online Published: April 15, 2020

doi:10.5539/ijbm.v15n5p73

URL: https://doi.org/10.5539/ijbm.v15n5p73

\begin{abstract}
The purpose of this paper is to suggest an instructional approach in the introductory business statistics course that utilizes relationships between separately introduced topics. The paper will explore three "useful relationships" that can assist classroom instruction: (1) the relationship between the simple arithmetic mean, the weighted arithmetic mean, and the expected value of a discrete probability distribution; (2) the relationship between the use of the multiplication rule to calculate the joint probability associated with two events, use of tree diagrams, and the use of the binomial and hypergeometric distributions; and (3) the relationship between the geometric mean and the compound interest rate. Each discussion includes detailed examples of calculations to demonstrate the relationships.
\end{abstract}

Keywords: statistics, teaching statistics, teaching pedagogy

\section{Introduction}

In most any courses of instruction, students receive a considerable amount of information that, to them, appears unrelated and isolated. This inability to relate topics is particularly apparent in the introductory business statistics course.

Students in an introductory business statistics course receive instruction in a variety of topics including descriptive statistics, probability and probability distributions, inferential statistics, and regression analysis. As part of the instruction, a large number of equations are utilized. In many cases each equation appears, to many students, to be totally unrelated to any material previously studied. In such circumstances, the students believe that each topic is independent and that the material learned previously does not help in understanding a new topic. Such thinking is really far from reality.

The reality is that there are many useful relationships that exist among different statistics topics. If these relationships are noted and explained, students are frequently able to learn new topics more easily. The learning process is supported by previously learned material, and thus the relative proportion of new material to learn is reduced, sometimes significantly. While some textbooks do a good job of identifying these relationships, an instructor may choose to supplement a text to accommodate alternate learning styles.

Students learn in different ways. As suggested by Fleming and Mills (1992), the primary four modes of learning are: (1) Visual, (2) Aural, (3) Read/Write, and (4) Kinesthetics [Hands-on]. However, regardless of how a student learns, reinforcement of a new topic by connecting a previous topic can be useful in developing the new topic.

This paper presents three "useful relationships" that can assist classroom instruction. The paper explores (1) the relationship between the simple arithmetic mean, the weighted arithmetic mean, and the expected value of a discrete probability distribution; (2) the relationship between use of the multiplication rule to calculate the joint probability associated with two events, use of tree diagrams, and the use of binomial and hypergeometric distributions; and (3) the relationship between the geometric mean and the compound interest rate. Each relationship will be discussed utilizing detailed examples.

\section{Material Studied}

While the use of relationships in teaching Statistics offers a fresh approach, a review of the literature reveals a variety of methodologies designed to enhance student learning. Kellogg's (1939) recognition of student fear as a primary challenges in teaching statistics led to his conclusion that "by changing teaching methods temporary improvement may be accomplished" (p. 305). Others have similarly cited the difficulty in teaching statistics as a 
basis for alternate teaching methods (Khan, 2013; Prabhakar, 2008).

Still others have focused on the importance of active forms of learning. In their literature review of how students learn statistics, Garfield and Ben-Zvi (2007) rely on the work of Keeler and Steinhorst (1995), Giraud (1997), Magel (1998), and Meletiou and Lee (2002) in concluding that cooperative learning generally yields positive results. Additionally, Hillmer (1996) proposes a problem-solving approach that aligns examples with the daily data analysis needs of managers. Johnson and John (2003) advocate for the use of demonstrations and experiments. Gandhi (2006) stresses the importance of communicating results, as do Green, Jones, and Bean (2015), who present a strategy for using scaffolded communication assignments to enhance depth of student learning.

The need for a variety of teaching methods, including active learning techniques, better accommodates differences in student learning styles. As a result of his review of statistics courses across multiple disciplines, Garfield (1995) offers eight principles for learning statistics. In doing so, he stresses the importance of regular assessment and an openness to alternate teaching methods. Strasser and Ozgur's review of teaching methodologies (1995) also highlights the use of presentations, demonstrations, and cases as important alternatives to lecture.

Further evidence is provided by Lockwood, Ng, and Pinto (2007), who apply diverse learning and teaching styles to the interpretation of statistical results. They use team projects as a way of encouraging cooperative learning and ultimately find improvements in attrition and student learning. Similarly, Dunn, Carey, Richardson, and McDonald (2016) explore the role of linguistic challenges in teaching statistics. They present several methods for overcoming these challenges, and ultimately encourage instructors to be flexible in their teaching methods and adapt to the needs of learners.

Existing research highlights the benefits of using multiple teaching methods. This paper offers useful relationships as one technique for using variety and repetition to enhance student learning.

\section{Methods and Techniques}

3.1 The Relationship between the Simple Arithmetic Mean, the Weighted Arithmetic Mean, and the Expected Value of a Discrete Probability Distribution

As part of the first few weeks of a basic statistics course, the following three equations are usually introduced. Equation (1) is for the simple arithmetic mean (sample data); Equation (2) is for the weighted arithmetic mean; and Equation (3) is for the expected value (for a discrete probability distribution).

Where: $\bar{X}=$ arithmetic mean

$$
\bar{X}=\frac{\Sigma X}{n}=\frac{X_{1}+X_{2}+X_{3}+\ldots+X_{n}}{n}
$$

$\mathrm{x}=$ each data item

$\mathrm{n}=$ number of data items

Where: $\bar{X}_{\mathrm{w}}=$ weighted arithmetic mean

$$
\bar{X} w=\frac{\sum(W X)}{\Sigma W}=\frac{W_{1} X_{1}+W_{2} X_{2}+w_{3} X_{3}+\ldots+W_{n} X_{n}}{w_{1}+w_{2}+w_{3}+\cdots+w_{n}}
$$

$\mathrm{X}=$ each data item

$\mathrm{W}=$ weight for each data item

$$
\mu=E(X)=\sum[x P(X=x)]=x_{1} P\left(X=x_{1}\right)+x_{2} P\left(X=x_{2}\right)+x_{3} P\left(X=x_{3}\right)+\ldots+x_{n} P\left(X=x_{n}\right)
$$

Where: $\mu=\mathrm{E}(\mathrm{X})=$ mean of a discrete probability distribution

$\mathrm{x}=$ each data item

$\mathrm{P}(\mathrm{X}=\mathrm{x})=$ probability of each data item

First, using the data set $(2,4,6,8,10)$, the relationship between Equation (1) and Equation (2) can be examined. Substituting the values $(2,4,6,8,10)$ into Equation (1) produces the following result.

$$
\begin{gathered}
\bar{X}=\frac{\sum x}{n}=\frac{2+4+6+8+10}{5}=\frac{30}{5} \\
\bar{X}=6
\end{gathered}
$$

Next, using Equation (2) and the same data set $(2,4,6,8,10)$ results in the following solution, with equal weights (arbitrarily choosing the weight $=$ three). 


$$
\begin{gathered}
\bar{X}_{w}=\frac{\sum(w x)}{\sum w}=\frac{3(2)+3(4)+3(6)+3(8)+3(10)}{3+3+3+3+3}=\frac{6+12+18+24+30}{15}=\frac{90}{15} \\
\bar{X} w=6
\end{gathered}
$$

Thus, by using a simple data set, the equivalency of Equation (1) and Equation (2) is demonstrated. This equivalency occurs when the weights (Ws in Equation (2)) are "equal". That is, if the values (such as 2, 4, 6, 8, 10) are equally important, Equation (1) or Equation (2) will produce the correct answer.

The next step is to relate Equation (2) to Equation (3). The first relationship to point out is that the $\mathrm{P}(\mathrm{X}=\mathrm{x}) \mathrm{s}$ in Equation (3) are really weights and thus they have the same importance in Equation (3) as the Ws have in Equation (2). Using the discrete probability distribution shown below, the equivalency of Equation (2) and Equation (3) can be demonstrated.

Table 1. Hypothetical discrete probability distribution

\begin{tabular}{cc}
\hline$\underline{\mathrm{x}}$ & $\underline{\mathrm{P}(\mathrm{X}=\mathrm{x})}$ \\
\hline 2 & 0.2 \\
4 & 0.2 \\
6 & 0.3 \\
8 & 0.2 \\
10 & 0.1 \\
\hline
\end{tabular}

Using Equation (3), the expected value (5.6) is calculated as shown below.

$$
\begin{gathered}
\mu=E(X)=\sum[x P(X=x)] \\
\mu=2(0.2)+4(0.2)+6(0.3)+8(0.2)+10(0.1) \\
\mu=0.4+.8+1.8+1.6+1.0 \\
\mu=5.6
\end{gathered}
$$

And using Equation (2), the weighted arithmetic mean computation yields the results below.

$$
\begin{gathered}
\bar{X} w=\frac{\sum(W X)}{\sum W}=\frac{.2(2)+.2(4)+.3(6)+.2(8)+.1(10)}{.2+.2+.3+.2+.1}=\frac{0.4+0.8+1.8+1.6+1.0}{1.0}=\frac{5.6}{1} \\
\bar{X} w=5.6
\end{gathered}
$$

After using Equation (2) and Equation (3), it can be observed that both equations yield the same value for the mean (expected value) of 5.6. This equivalency occurs because the probability numbers are the same as weights. For example, referring to Table 1 , the variable $(\mathrm{x}=2)$ has $\mathrm{P}(\mathrm{x}=2)=0.2$, and variable $(\mathrm{x}=10)$ has $\mathrm{P}(\mathrm{x}=10)=$ 0.1 , thus $\mathrm{x}=2$ is twice as important as $\mathrm{x}=10$. Consequently, the probability numbers are really weights which allows the use of Equation (2) or Equation (3).

Summarizing the preceding discussion, it can be pointed out that Equation (1), used to calculate the simple arithmetic mean, is a special case of Equation (2) where the weights $(\mathrm{Ws})$ are all equal to one $(\mathrm{W}=1)$. Further, it can be pointed out that Equation (2) and Equation (3) are equivalent because the $\sum W=\sum P=1.00$. So, both equations are utilizing the same weighting scheme and thus yield the same result.

Finally, it is also useful to demonstrate that when the weights (also probabilities) are equal that Equations (1), (2), and (3) will yield identical answers when using the same data set.

Table 2. Comparison of three data sets

\begin{tabular}{ccccc}
\hline $\begin{array}{c}\text { Data Set For } \\
\text { Equation (1) }\end{array}$ & \multicolumn{2}{c}{$\begin{array}{c}\text { Data Set for } \\
\text { Equation (2) }\end{array}$} & \multicolumn{2}{c}{$\begin{array}{c}\text { Data Set for } \\
\text { Equation (3) }\end{array}$} \\
\hline$\underline{\mathrm{x}}$ & $\underline{\mathrm{x}}$ & $\underline{\mathrm{W}}$ & $\underline{\mathrm{x}}$ & $\underline{\mathrm{P}(\mathrm{X}=\mathrm{x})}$ \\
3 & 3 & 3 & 3 & .25 \\
6 & 6 & 3 & 6 & .25 \\
9 & 9 & 3 & 9 & .25 \\
12 & 12 & 3 & 12 & .25 \\
\hline
\end{tabular}




$$
\begin{gathered}
\bar{X}=\frac{\sum X}{n}=\frac{3+6+9+12}{4}=\frac{30}{4}=7.5 \\
\bar{X}=\frac{\sum W X}{n}=\frac{(3)(3)+(3)(6)+(3)(9)+(3)(12)}{3+3+3+3}=\frac{9+18+27+36}{12}=\frac{90}{12}=7.5 \\
\mu=E(X)=\sum[x P(X=x)]=3(.25)+6(.25)+9(.25)+12(.25)=0.75+1.50+2.25+3=7.5
\end{gathered}
$$

3.2 The Relationship between Joint Probabilities Calculated Using the Multiplication Rule, the Binomial and Hypergeometric Discrete Probability Distributions, and Tree Diagrams

\subsubsection{The Binomial Comparison}

The determination of probability numbers using probability rules and discrete probability distributions generally appear in separate chapters in a basic statistics book and frequently appear to the student to be unrelated discussions. The purpose of the following presentation is to connect the two types of calculations. The following hypothetical situation will be utilized.

\section{GIVEN: An urn with 6 red marbles and 4 green marbles}

REQUIRED: Determine the probability of selecting one red marble using two draws with replacement

The multiplication rule for two independent events is presented below [Equation (6)].

$$
\mathrm{P}(\mathrm{A} \text { and } \mathrm{B})=\mathrm{P}(\mathrm{A}) \cdot \mathrm{P}(\mathrm{B})
$$

Where: $\mathrm{P}(\mathrm{A}$ and $\mathrm{B})=$ joint probability that both $\mathrm{A}$ and $\mathrm{B}$ will occur

$\mathrm{P}(\mathrm{A})=$ simple probability that event A will occur.

$\mathrm{P}(\mathrm{B})=$ simple probability that event $\mathrm{B}$ will occur.

Using the multiplication rule to calculate the joint probability of two independent events (replacement is used), the probability of selecting one red marble is determined by identifying the number of ways that one red marble can occur (in this case it will be (red and green) and (green and red)) and calculating the associated probabilities. Then the probabilities must be summed as shown below.

$$
\mathrm{P}(\mathrm{R})=6 / 10=0.6 \quad \mathrm{P}(\mathrm{G})=4 / 10=0.4
$$

$$
\begin{aligned}
\mathrm{P}(\text { one red })=\quad \mathrm{P}(\mathrm{R} \text { and } \mathrm{G})+\mathrm{P}(\mathrm{G} \text { and } \mathrm{R}) \text { [using Equation }(4) \text { twice }] \\
=\mathrm{P}(\mathrm{R}) \mathrm{P}(\mathrm{G})+\mathrm{P}(\mathrm{G}) \mathrm{P}(\mathrm{R}) \\
=(0.6)(0.4)+(0.4)(0.6) \\
=0.24+0.24 \\
=0.48
\end{aligned}
$$

Using the multiplication equation [Equation (4], the probability of one red which can happen as red-green or green-red is determined to be 0.48 . The tree diagram shown below in Figure 1 demonstrates the same situation, but more clearly portrays the RG and GR outcomes and the need to add the probabilities together. Note, the inner branches are the branches of interest. The outer branches show that $\mathrm{P}($ two red $)=0.36$ and $\mathrm{P}($ zero red $)=0.16$. The urn shown in Figure 1 has the same contents for both draws.



Figure 1. Tree Diagram for the Probability of One Red Marble, Two Draws With Replacement 
Now, let's see how the binomial does the same thing. The binomial distribution utilizes Equation (5) to calculate exact probabilities of specific outcomes and is appropriate when there are two outcomes (such as red and green) and replacement is utilized.

$$
P(X=x) \quad={ }_{n} C_{x} p^{x}(1-p)^{n-x}
$$

Where: $\mathrm{P}(\mathrm{X}=\mathrm{x})=$ probability that a particular event $(\mathrm{X}=$ number $)$ will occur

$\mathrm{n}=$ number of trials

$\mathrm{x}=$ number of items of interest

$$
\left.{ }_{n} C_{x}=\frac{n !}{X !(n-X) !} \text { (combinatoriol formula }\right]
$$

$\mathrm{p}=$ probability of item of interest

$1-p=$ probability of other item

Thus the following calculations can be made.

Probability of one red marble (item of interest) when $\mathrm{n}=2, \mathrm{x}=1, \mathrm{p}=0.6$.

$$
\begin{aligned}
P(X=x) & ={ }_{n} C_{x} p^{x}(1-p)^{n-x} \\
P(X=1) & ={ }_{2} C_{1}(0.6)^{1}(0.4)^{1} \\
= & 2(0.6)(0.4)
\end{aligned}
$$

$P(X=1)=0.48$ [same answer produced by Eq. 4 and tree diagram (Figure 1)]

Probability of two red marbles when $\mathrm{n}=2, \mathrm{x}=2, \mathrm{p}=0.6$.

$$
\begin{gathered}
P(X=x)={ }_{n} C_{x} p^{x}(1-p)^{n-x} \\
P(X=2)={ }_{2} C_{2}(0.6)^{2}(0.4)^{0} \\
=1(0.36)(1) \\
P(X=2)=0.36
\end{gathered}
$$

Probability of zero red marbles when $\mathrm{n}=2, \mathrm{x}=0, \mathrm{p}=0.6$.

$$
\begin{gathered}
P(X=x)={ }_{n} C_{x} p^{x}(1-p)^{n-x} \\
P(X=0)={ }_{2} C_{0}(0.6)^{0}(0.4)^{2} \\
=1(1)(0.16) \\
P(X=0)=0.16
\end{gathered}
$$

Thus, we have demonstrated that $\mathrm{P}(\mathrm{X}=$ one red) [probability of selecting one red marble in two draws using replacement $]=0.48$ can be calculated using: (1) the multiplication equation for two independent events [Equation (4)], (2) a tree diagram, or (3) the binomial distribution [Equation (5)]. Now let's examine the hypergeometric distribution.

3.2.2 The Hypergeometric Comparison

Now, let's examine the same situation when the experiment is conducted using no replacement (dependent events). The following situation will be utilized.

GIVEN: An urn with 6 red marbles and 4 green marbles

REQUIRED: Probability of selecting one red marble using two draws without replacement

First, as we did with the binomial situation, we will calculate the probability of one red marble using the multiplication rule when there are dependent events (no replacement). Equation (6) is given below.

$$
\mathrm{P}(\mathrm{A} \text { and } \mathrm{B}) \quad=\quad \mathrm{P}(\mathrm{A}) \cdot \mathrm{P}(\mathrm{B} \backslash \mathrm{A})
$$

Where: $\mathrm{P}(\mathrm{A}$ and $\mathrm{B})=$ probability that both $\mathrm{A}$ and $\mathrm{B}$ will occur

$\mathrm{P}(\mathrm{A})=$ simple probability that event $\mathrm{A}$ will occur

$\mathrm{P}(\mathrm{B} \backslash \mathrm{A})=$ conditional probability that event $\mathrm{B}$ will occur after event $\mathrm{A}$ has occurred.

The conditional probability provides the probability that a particular event will occur after a previous event has 
already occurred. For example, when there are ten marbles in the urn and one marble is drawn and not replaced, there are only nine marbles remaining in the urn. Thus if a red marble [six reds and four greens in the urn] is drawn and not replaced, the second draw is from an urn that now contains five reds and four greens. So, the second draw is a conditional probability (no replacement) and expressed as $P(G \backslash R)$ [probability that green will occur given that red has already occurred]. Thus the $\mathrm{P}(\mathrm{G} \backslash \mathrm{R})=4 / 9=0.444$. Now, let's complete the example.

$$
\begin{gathered}
P(R)=0.6 \quad P(G)=0.4 \\
P(\text { one red })=P(R \text { and } G)+P(G \text { and } R) \\
=P(R) P(G \backslash R)+P(G) P(R \backslash G) \\
=(0.6)(0.444)+(0.4)(0.666) \\
=0.2664+0.2664 \\
P(\text { one red })=0.5328 \text { or } 0.533
\end{gathered}
$$

Using the multiplication equation and noting that the events are dependent, the probability of one red is determined to be 0.533 . Note that the conditional probabilities are $P(G \backslash R)=0.444(4 / 9)$ and $P(R \backslash G)=0.666$ $(6 / 9)$.

$$
\mathrm{P}(\text { zero red })=\mathrm{P}\left(\mathrm{G}_{1}\right) * \mathrm{P}\left(\mathrm{G}_{2} \mid \mathrm{G}_{1}\right)=(4 / 10) *(3 / 9)=12 / 90
$$

$\mathrm{P}($ zero red $)=0.133$

$\mathrm{P}($ two red $)=\mathrm{P}\left(\mathrm{R}_{1}\right) * \mathrm{P}\left(\mathrm{R}_{2} \mid \mathrm{R}_{1}\right)=(6 / 10) *(5 / 9)=30 / 90$

$\mathrm{P}($ two red $)=0.333$

Now, let's examine the same situation using a tree diagram. Figure 2 presents the tree diagram calculation and makes it easier to see the red-green $(R \backslash G)$ and green-red $(G \backslash R)$. Note that Figure 2 shows three different urns because the contents change in the second draw and differ depending on whether the top branch or lower branch of the second draw is being considered.

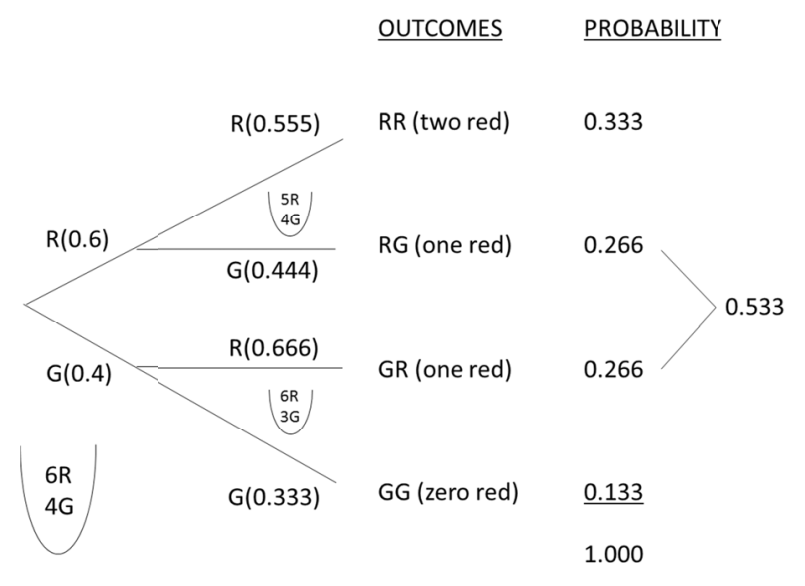

Figure 2. Tree Diagram for the probability of one red marble, two draws with no replacement

Thus, from Figure 2, the following can be observed.

$$
\begin{gathered}
\mathrm{P}(\text { one red })=0.533[0.266+0.266] \\
\mathrm{P}(\text { zero red })=0.133 \\
\mathrm{P}(\text { two red })=0.333
\end{gathered}
$$

Next, we will examine how the hypergeometric probability distribution solves the same problem utilizing Equation (7). Remember, there are six red marbles, four green marbles, and two marbles selected without replacement.

$$
P(X=x) \quad=\frac{{ }_{N_{1}} C_{x N_{2}} C_{n-x}}{{ }_{N} C_{n}}
$$


Where: $\mathrm{P}(\mathrm{X}=\mathrm{x})=$ probability that a particular event $[\mathrm{X}=$ number $]$ will occur

$\mathrm{X}=$ number of items of interest in the sample

$\mathrm{N}_{1}=$ number of items of interest in the finite population

$\mathrm{N}_{2}=$ number of all other items in the finite population

$\mathrm{N}=\mathrm{N}_{1}+\mathrm{N}_{2}$

$\mathrm{n}=$ sample size selected with no replacement.

Using Equation (7), the following calculations are made.

Probability of one red marble when $\mathrm{n}=2, \mathrm{x}=1, \mathrm{~N}_{1}=6$, and $\mathrm{N}_{2}=4$

$$
\begin{gathered}
P(X=1)=\frac{{ }_{N_{1}} C_{x{ }_{2}} C_{n-x}}{{ }_{N} C_{n}}=\frac{{ }_{6} C_{14} C_{1}}{{ }_{10} C_{2}}=\frac{\left[\frac{6 !}{1 !(6-1) !}\right]\left[\frac{4 !}{1 !(4-1) !}\right]}{\frac{10 !}{2 !(10-2) !}} \\
=\frac{\left[\frac{6 \cdot 5 !}{1 ! 5 !}\right]\left[\frac{4 \cdot 3 !}{1 ! 3 !}\right]}{\frac{10 \cdot 9 \cdot 8 !}{(2 !)(8 !)}} \\
P(X=1)=\frac{(6)(4)}{\frac{90}{2}}=\frac{24}{45}=0.533
\end{gathered}
$$

Where: $\mathrm{N}=10$

$\mathrm{N}_{1}=6$ (Red)

$\mathrm{N}_{2}=4$ (Green)

$\mathrm{n}=2$

$\mathrm{x}=1$ (red)

$\mathrm{n}-\mathrm{x}=2-1=1$ (green)

Probability of two red marbles when $\mathrm{n}=2, \mathrm{x}=2, \mathrm{~N}_{1}=6$, and $\mathrm{N}_{2}=4$

Probability of zero red marbles

$$
P(X=2) \quad=\quad \frac{{ }_{N_{1}} C_{x}{ }_{N} C_{n-x}}{{ }_{N} C_{n}}=\frac{{ }_{6} C_{24} C_{0}}{{ }_{10} C_{2}}=\frac{15}{45}=0.333
$$

$$
P(X=0)=\frac{{ }_{N_{1}} C_{x N_{2}} C_{n-x}}{{ }_{N} C_{n}}=\frac{{ }_{6} C_{04} C_{2}}{{ }_{10} C_{2}}=\frac{6}{45}=0.133
$$

As we did with the binomial, we have now demonstrated the same situation under the condition of selecting without replacement which makes the hypergeometric probability distribution the appropriate discrete probability distribution to employ. The $\mathrm{P}(\mathrm{X}=$ one red $)$ [probability of selecting one red marble in two draws without replacement $=0.533$ has been calculated three different ways: $(1)$ the multiplication equation for dependent events, (2) a tree diagram, and (3) the hypergeometric probability distribution. The fact that each calculation yields the same answer confirms the relationship between the different solution approaches.

\subsection{The Relationship between the Geometric Mean and the Compound Interest Rate}

The measure of central tendency known as the geometric mean is calculated using Equation (8). Arithmetically,

$$
G M=\sqrt[n]{\left(X_{1}\right)(X)_{2}\left(X_{3}\right) \ldots\left(X_{n}\right)}
$$

Where: $\mathrm{x}=$ each data item

$\mathrm{n}=$ number of data items

For example, consider the four data items $(6,8,9,12)$. The geometric mean would be (using Equation (8)):

$$
G M=\sqrt[4]{6 \cdot 8 \cdot 9 \cdot 12}=\sqrt[4]{5184}=8.4853
$$

At this point, the calculation of GM appears to produce a rather abstract number. Actually, this calculation has a significant financial interpretation: the geometric mean is calculating the average per period change for a given 
data set. Consider the following example.

Table 3. Geometric mean calculation

\begin{tabular}{lll}
\hline$(1)$ & $(2)$ & $(3)$ \\
Period & Data $(\$)$ & Percent of Previous Period \\
\hline 1 & 1000 & -- \\
2 & 1075 & 1.0750 \\
3 & 1120 & 1.0419 \\
4 & 1200 & 1.0714 \\
5 & 1300 & 1.0833 \\
\hline
\end{tabular}

Column (2) presents five data items occurring in five sequential periods (column (1)). The third column calculates the ratio of two adjacent columns: for example, Data item from period (3) divided by Data item from period $(2)=1120 / 1075=1.0419$. Using the column (3) information and Equation (8), the geometric mean is calculated as follows

$$
\begin{gathered}
G M=\sqrt[4]{(1.0750)(1.0419)(1.0714)(1.0833)} \\
G M=\sqrt[4]{1.2999747}=(1.2999747)^{.25} \\
G M=1.06778
\end{gathered}
$$

and the financial interpretation is shown below.

Average percentage change per period $=\mathrm{GM}-1=1.06778-1=0.06778$.

Financially, this average percentage change per period is the equivalent of an average rate of interest needed to grow an initial value to a future value in a particular number of periods. This growth effect is known as the compounding effect. That is, each year, the principle earns interest; and after year one, the interest also earns interest. So, to accurately determine the future value of an initial value that increases at a particular interest rate, the geometric mean is appropriate.

To demonstrate the financial interpretation, Equation (9) is utilized.

$$
\text { Future value }=\left[\text { Initial Value }{ }^{*}[1+\text { average percentage change per period }]^{\mathrm{n}-1}\right.
$$

Where: Future value $=$ the final value after the initial value is increased by the number of compounding periods by the average percentage increase per period

Initial value $=$ first data item

Average percentage change per period $=\mathrm{GM}-1$

$\mathrm{n}=$ number of data items

$\mathrm{n}-1=$ number of compounding periods

Using Equation (9), the future value of 1000 after four (5-1) periods of change is calculated as follows

$$
\text { Future value }=(1000)(1+0.06778)^{4}=(1000)(1.29995)=1299.95 \text { or } 1300.00
$$

Referring back to Table 3, it is noted that the period one value of $\$ 1000$ becomes $\$ 1300$ in period five after four changes in the five periods.

Now, a final comment for this section introduces Equation (10), which is a more direct (quicker) calculation for the average percentage change per period.

$$
\text { Average percentage change per period }=\sqrt[n-1]{\frac{\text { Future Value }}{\text { Initial Value }}}-1
$$

Where: Future value $=$ ending desired value

Initial value $=$ beginning value

$\mathrm{n}-1=$ number of compounding periods

Then, using Equation (10) and previous data: 
Average percentage change per period $=\sqrt[4]{\frac{1,300}{1,000}}-1=\sqrt[4]{1.3}-1=(1.3)^{.25}-1=1.06778-1$

Average percentage change per period $=0.06778$

\section{Conclusion}

The purpose of this paper is to present and encourage the utilization of "relationships" that are present in statistics but often appear to be isolated topics to students. Three such relationships are discussed in detail: (1) the relationship between the simple arithmetic mean, the weighted arithmetic mean, and expected value of a discrete probability distribution; (2) the relationship between the use of the multiplication rule to calculate joint probabilities, use of tree diagrams, and the use of the binomial and hypergeometric probability distributions; and (3) the relationship between the geometric mean and the compound interest rate. Identifying, discussing, and demonstrating "relationships" such as the three discussed in this paper will assist the student in understanding more fully relationships that are not immediately obvious.

The use of detailed examples to demonstrate these three handy relationships incorporates both use of equations and where appropriate, the use of tree diagrams. Using equations and tree diagrams coupled with a detailed discussion of the examples reaches several different learning modes:

(1) Aural through hearing a thorough lecture demonstrating the use of the equations utilizing example problems plus a thoughtful selection and discussion of frequently asked questions.

(2) Visual through seeing the equations and diagrams (such as a tree diagram) presented on the board or using powerpoint plus providing a detailed handout of the equation and pictures such as tree diagrams for the student to have and review.

(3) Read/write through providing detailed printed material of equations and problem solutions plus devoting class time to reading and writing solutions to problems incorporating the previously discussed equations.

(4) Kinesthetic through a combination of seeing equations and tree diagrams plus devoting class time to the actual drawing of tree diagrams and creating sample problems that demonstrate the equations that were discussed in the lecture.

\section{References}

Dunn, P. K., Carey, M. D., Richardson, A. M., \& McDonald, C. (2016). Learning the Language of Statistics: Challenges and Teaching Approaches. Statistics Education Research Journal, 15(1), 8-27.

Fleming, N. D., \& Mills, C. (1992). Not another inventory, rather a catalyst for reflection. To improve the academy, 11(1), 137-155. https://doi.org/10.1002/j.2334-4822.1992.tb00213.x

Gandhi, B. (2006). Improving the teaching of statistics in business education: lessons and reflections. Proceedings, 7th International Conference on Teaching Statistics, Salvador, Bahia..

Garfield, J. (1995). How students learn statistics. International Statistical Review/Revue International de Statistique, 63(1), 25-34. https://doi.org/10.2307/1403775

Garfield, J., \& Ben-Zvi, D. (2007). How students learn statistics revisited: A current review of research on teaching and learning statistics. International statistical review, 75(3), 372-396. https://doi.org/10.1111/j.1751-5823.2007.00029.x

Giraud, G. (1997). Cooperative learning and statistics instruction. Journal of Statistics Education, 5(3), 1-12. https://doi.org/10.1080/10691898.1997.11910598

Green, G., Jones, S., \& Bean, J. C. (2015). Teaching real-world applications of business statistics using communication to scaffold learning. Business and Professional Communication Quarterly, 78(3), 314-335. https://doi.org/10.1177/2329490615588908

Hillmer, S. C. (1996). A problem-solving approach to teaching business statistics. The American Statistician 50(3), 249-256. https://doi.org/10.1080/00031305.1996.10474392

Johnson, D. G., \& John, J. A. (2003). Use of demonstrations and experiments in teaching business statistics. Journal of Applied Mathematics and Decision Sciences, 7(2), 93-103. https://doi.org/10.1155/S1173912603000099

Keeler, C. M., \& Steinhorst, R. K. (1995). Using small groups to promote active learning in the introductory statistics course: A report from the field. Journal of Statistics Education, 3(2), https://doi.org/10.1080/10691898.1995.11910485 
Kellogg, L. S. (1939). Some Problems in Teaching Elementary Statistics. Journal of the American Statistical Association, 34(206), 299-306. https://doi.org/10.1080/01621459.1939.10502384

Khan, R. N. (2013). Teaching first-year business statistics three ways. Proceedings of the 9th DELTA Conference on Teaching and Learning of Undergraduate Mathematics and Statistics.

Lockwood, C. A., Ng, P., \& Pinto, J. (2007). An interpretive business statistics course encompassing diverse teaching and learning styles. Academy of Educational Leadership Journal, 11(1), 11-23. https://doi.org/10.1111/j.1467-8578.1984.tb00201.x

Magel, R. C. (1998). Using cooperative learning in a large introductory statistics class. Journal of Statistics Education, 6(3). https://doi.org/10.1080/10691898.1998.11910621

Meletiou-Mavrotheris, M., \& Lee, C. (2002). Teaching students the stochastic nature of statistical concepts in an introductory statistics course. Statistics Education Research Journal, 1(2), 22-37.

Prabhakar, G. P. (2008). Stats for the terrified: Impact of different teaching and learning approaches in the study of business statistics. International Journal of Business and Management, 3(6), 21-28. https://doi.org/10.5539/ijbm.v3n6p21

Strasser, S. E., \& Ozgur, C. (1995). Undergraduate business statistics: A survey of topics and teaching methods. Interfaces, 25(3), 95-103. https://doi.org/10.1287/inte.25.3.95

\section{Copyrights}

Copyright for this article is retained by the author(s), with first publication rights granted to the journal.

This is an open-access article distributed under the terms and conditions of the Creative Commons Attribution license (http://creativecommons.org/licenses/by/4.0/). 